\title{
Application of the MSB pollution-flushing model to Great Salt Pond on Block Island
}

\author{
S. Mecca ${ }^{1}$, R. Barber ${ }^{2}$, G. Mellor ${ }^{3} \&$ G. Walsh ${ }^{1}$ \\ ${ }^{I}$ Department of Engineering-Physics-Systems, Providence College, \\ Providence, RI, USA \\ ${ }^{2}$ Computational Science and Engineering Department, CCLRC \\ Daresbury Laboratory, Warrington, UK \\ ${ }^{3}$ Princeton University, Princeton, NJ, USA
}

\begin{abstract}
The MSB single-embayment model of pollution flushing from a tidal basin has been applied to Great Salt Pond on Block Island and the results compared to an unpublished Rhodamine dye study conducted in 1986. The MSB model is based on the analytical tidal prism formulation developed by Barber. Both approaches have previously been validated against physical hydraulic modelling tests conducted on an idealised constant-depth rectangular basin, and the MSB model has been found to give excellent agreement against the laboratory data. However, until this present work, the MSB model has not been applied to a real embayment.

The present paper details a simulation of pollution flushing from Great Salt Pond following the release of Rhodamine dye. Results for various values of the pollution return-flow parameter, $b$, have been obtained and the agreement between the measured dye concentration data and the model predictions is shown to be very good for a suitably chosen value of $b$.

Keywords: tidal prism, pollution flushing, tidal embayment, Great Salt Pond Block Island.
\end{abstract}

\section{Introduction}

The MSB single-embayment model [1] offers a graphical and numerical representation of the process of pollution flushing from well-mixed tidal embayments. The model, which is written in Stella (Stella is a product of ISEE 
Systems, Inc., formerly High Performance Systems of Hanover, New Hampshire, USA.), allows for realistic basin bathymetries [2] and the dynamic loading of pollutants [3]. The governing rate equations driving the model are the same as those found in the analytical tidal prism model developed by Barber [4] for constant pollution loading and simple basin geometries. The governing equations are derived from the following mass flow equation:

$$
\frac{d(C V)}{d t}=V \frac{d C}{d t}+C \frac{d V}{d t}=Q C,
$$

where $Q$ is the discharge through the entrance to the embayment, $C$ is the instantaneous pollutant concentration and $V$ is the volume of the embayment at time, $t$. During the ebb flow period, $d V / d t=Q$, allowing the $Q C$ term on the right-hand side of eqn. (1) to be cancelled with the $C d V / d t$ term on the left. During the flood flow period, the $Q C$ term on the right-hand side of the equation can be assumed to be zero, provided the pollution return-flow rate into the basin is ignored (the modelling of pollution return flow will be considered later in the paper). This results in two rate equations for $d C / d t$, one for the ebb and another for the flood conditions. The MSB model [1] employs the basic state variable approach used in systems dynamics to represent the governing mass flow rate equations, treating the time-varying pollutant concentration, $C$, in the embayment as a level. The present paper applies this model to Great Salt Pond on Block Island, where in 1986 a Rhodamine dye study was conducted and the results presented in an unpublished report [5].

\section{Great Salt Pond}

Great Salt Pond is situated on Block Island, which is part of the State of Rhode Island and situated in the Atlantic Ocean at the entrance to Long Island Sound at a latitude of $41.191^{\circ} \mathrm{N}$ and a longitude of $71.575^{\circ} \mathrm{W}$. The population of Block Island is little more than 1000 but this swells to 10,000 or more during the summer. Much of this increase is related to boating activities around Great Salt Pond. For the past two decades, shell fishing has been closed in this embayment due to high levels of faecal coliforms resulting from boating discharges and runoff conditions. To combat pollution problems, recent regulations have mandated 'no discharge' activities within the area.

The sensitivity of Great Salt Pond to pollution in the mid-1980s led the Department of Health and Human Services, Public Health Service, of the Shellfish Sanitation Branch of the Food and Drug Administration to conduct a Rhodamine dye study in the embayment [5]. This study was carried out during the period between $2^{\text {nd }}$ October and $6^{\text {th }}$ October 1986 to ascertain the flushing rate of the embayment.

\section{Synopsis of the Rhodamine dye study}

The dye study report [5] indicates that 3.5 gallons of Rhodamine WT dye (the equivalent of $7.0 \mathrm{lbs}$ dry weight) were uniformly released over a period of 10 
hours and 41 minutes at a position in a mooring area, as shown in Figure 1. According to the report, "flushing of the Great Salt Pond was slow. Appreciable amounts of dye did not escape from the pond until two complete tidal cycles (about 30 hours) had occurred. The dye was mixed fairly well both vertically and horizontally after 24 hours and became more homogeneous throughout the pond after 48 hours".

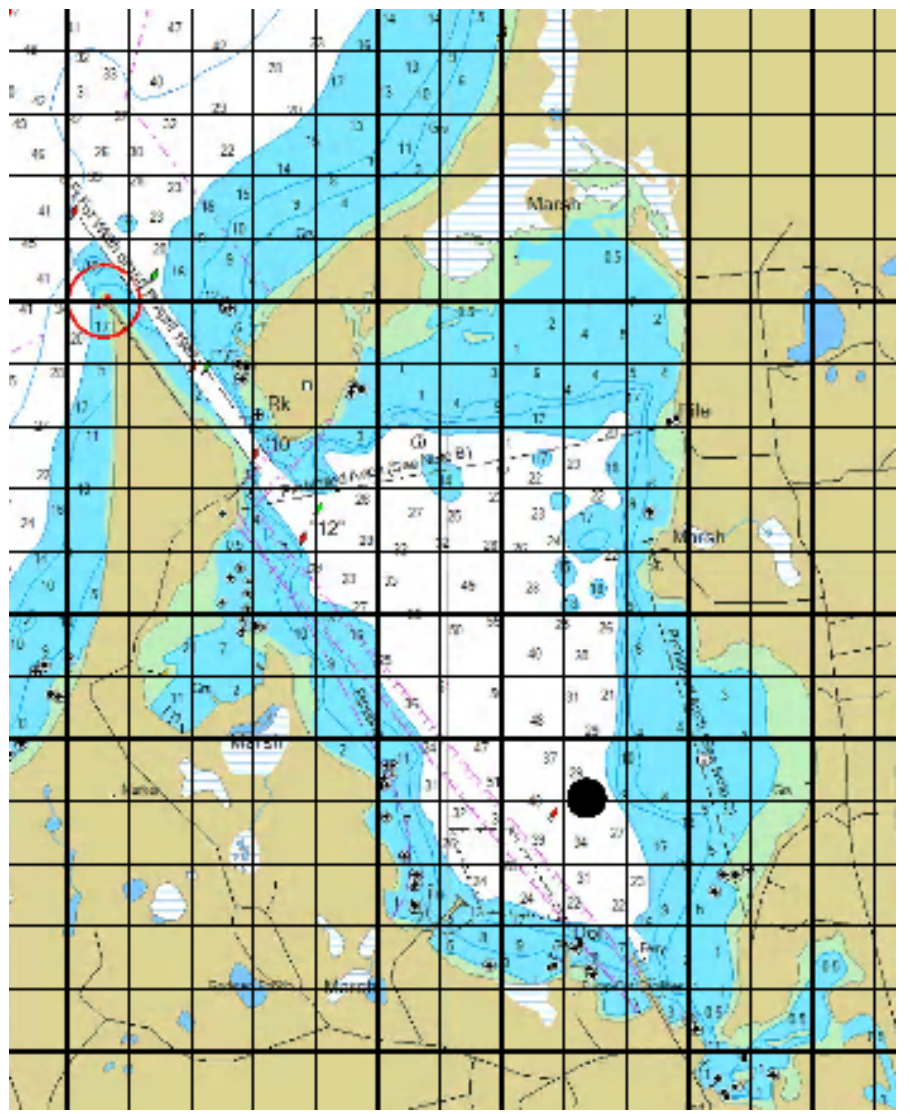

Figure 1: Bathymetry of Great Salt Pond, Block Island and the dye release position () used for the pollution flushing study. The chart has been overlaid with a grid in order to acquire the depth data for the MSB pollution-flushing model. Reproduced from NOAA chart number US 13217.

A fairly common procedure was used to trace the dye concentration: a calibrated field fluorometer that was sensitive to ppb was used and corrections for differences in the temperature between field and calibration conditions were applied. To study the dispersion of the Rhodamine dye, concentration measurements were made in both the horizontal and vertical directions at eight specific intervals during the study period. 


\section{Application of the MSB model}

The MSB model assumes a well-mixed basin and, from the aforementioned dye study report, it would appear that this feature applies to Great Salt Pond. In the field study, the dye was released at a single point well within the embayment and it was found that there was no appreciable escape of dye from the basin for about 30 hours following release, by which time the dye was well distributed both vertically and horizontally.

The simulations were initiated by applying an instantaneous pulse of dye at $t=29.17$ hours with an initial concentration that was estimated from the total mass of dye and the volume of the embayment. The MSB model is shown in Figure 2 and has a similar structure to that used in previous single embayment studies $[1,3]$ except for the bathymetry and tidal functions. In the earlier theoretical studies, these functions were modelled using a constant bathymetry and a simple sinusoidal variation with time. For the Great Salt Pond analysis, the tidal dynamics were represented using the water level variations measured in the dye study and shown in Figure 3. NOAA-predicted tides were compared with actual tidal measurements and the maximum tidal lag during the study period was just 13 minutes according to the report [5].

The upper bar on Figure 3 represents the period of dye release and the lower bars represent the periods during which the dye concentration measurements were collected. The first five sets of measurements focused on following the movement of the dye through the basin. During these periods, the study indicates that there was no appreciable loss of dye through the entrance channel. The last three sets of measurements, taken when the dye had been thoroughly mixed in the basin, were converted to lbs of dye remaining in the pond. From the study report [5], all the dye was reported as still residing in the embayment until about 29.17 hours after release.

The last three data sampling periods provide an opportunity to compare our model simulations against the field data. An array of grid points representing the bathymetry of Great Salt Pond was established and the MSB model was run for a simulation time of 114 hours with a time step of 0.005 hours. The model was set up with an initial dye concentration at $t=29.17$ hours that was equivalent to a concentration of $7 \mathrm{lbs}(3.18 \mathrm{~kg})$ of Rhodamine dye uniformly distributed throughout the entire embayment. The basin has a volume of $9.8 \times 10^{6} \mathrm{~m}^{3}$ of seawater equivalent to a mass of $10.05 \times 10^{9} \mathrm{~kg}$. Dividing the pollutant mass by the basin seawater mass gives an initial pollutant concentration of 0.32 parts per billion (ppb).

One of the crucial parameters in the MSB model is the pollution return-flow factor, $b$. This parameter is used to modify the volume of the tidal prism to account for the return of polluted water during the flood tide. This methodology has been discussed by Barber [4] and more theoretically by Sanford et al. [6]. The volume-modifying factor is taken as $(1-b)$, where $b$ varies between 0 , for no return flow, and 1, for total return flow. The estimation of the pollution returnflow factor for Great Salt Pond will be discussed further in the next section. 


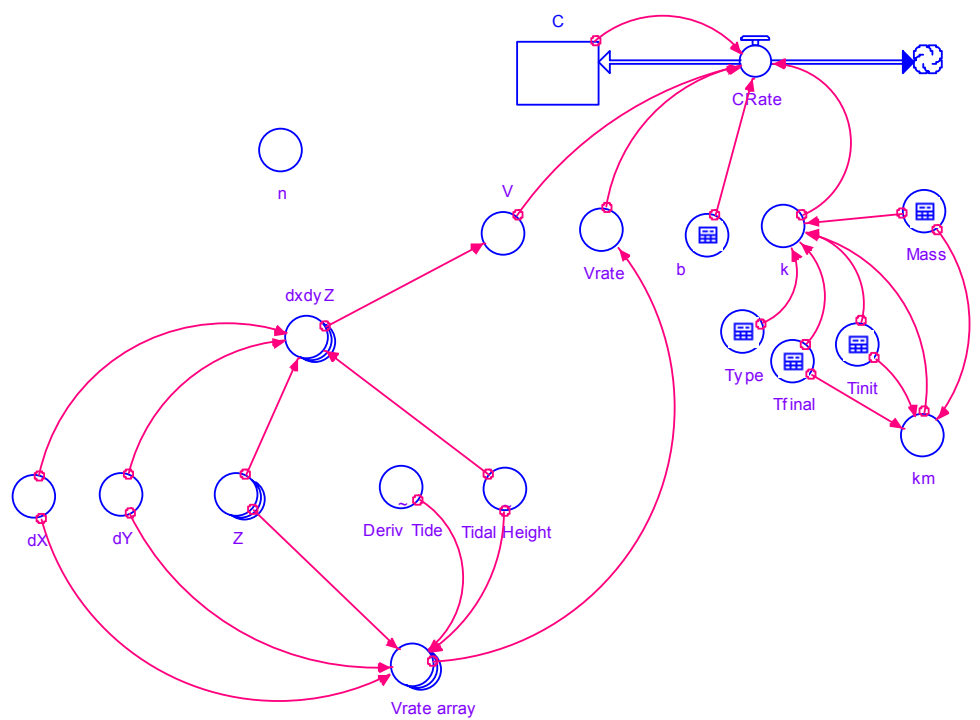

$C(t)=$ Concentration of pollution

CrateFlood $=$ Rate of change in pollution concentration during flood tide.

CrateEbb $=$ Rate of change in pollution concentration during ebb tide.

$b=$ Pollution return factor

$\mathrm{k}=$ Pollution loading rate (mass per unit time)

$\mathrm{km}=$ The highest value of $\mathrm{k}$

$\mathrm{n}=$ Internal variable used to keep track of tidal cycles

Period $=12.42$ hours in a tidal cycle

Tidal_Height $=$ height above mean low tide $(\mathrm{m})$

$\mathrm{V}=$ Volume of the embayment (m3)

Vrate $=$ Change in volume $V$ over time based on tides

$\mathrm{dX}=$ Length of grid block

$d x d y Z[i, j]=$ Volume of every block in the embayment grid at time $(t)$

$d Y=$ Width of grid block

max Tide $=$ Maxtidal swing $(\mathrm{m})$

Deriv Tide $=$ Derivative of Tidal Height

$Z[i, j]=$ Bathymetric data array for embayment

Mass $=$ The total amount of pollutant to be dumped during a tidal cycle $(\mathrm{kg})$

Tinit=The time at which the polluting starts (hrs)

Tfinal=The time at which the polluting ends (hrs)

Type=This paramter decides the type of loading function to be used.

Type 1 is a constant loading

Type 2 is a user definable step function that is 0 until Tinit and is a constant value between Tinit and Tfinal and 0 again after Tfinal.

Type 3 is an inclining ramp function with a definable start and end time.

Type 4 is an instaneous pulse.

Figure 2: $\quad$ MSB single-embayment model applied to Great Salt Pond. 


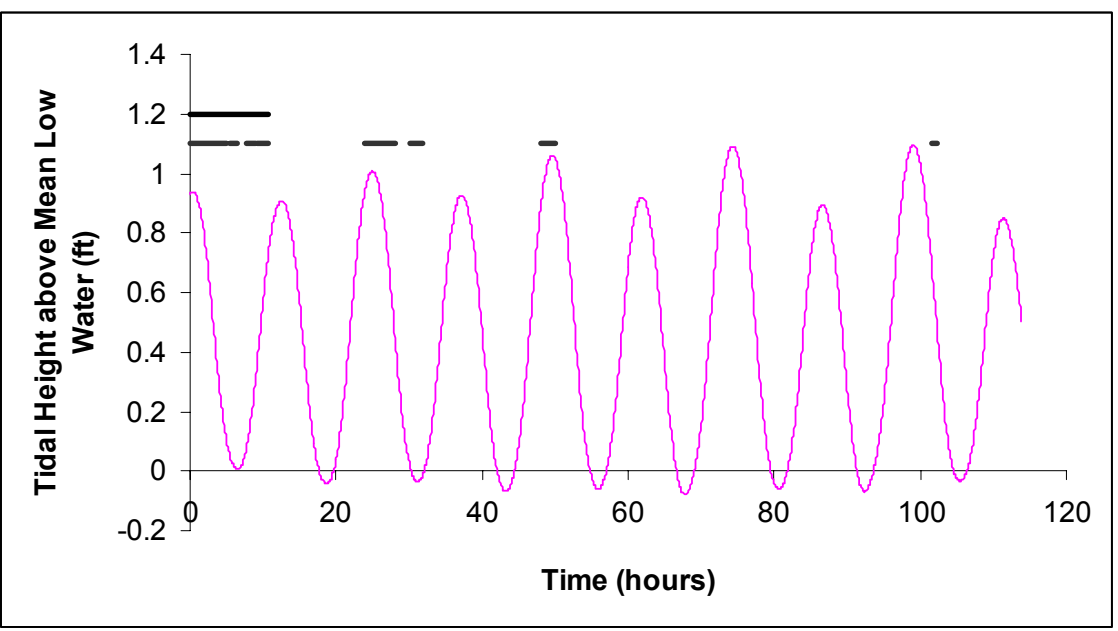

Figure 3: Tidal variations used in the present study. The upper horizontal bar shows the period of dye release while the lower bars represent the data measurement periods.

\section{Results}

In order to run the model, it was necessary to choose a value for the pollution return-flow parameter, $b$. It was decided to run the model with different values of $b$ and determine the value giving the best 'fit' to the data. Figure 4 shows the predicted concentration profile as a function of time for $b=0.25$.

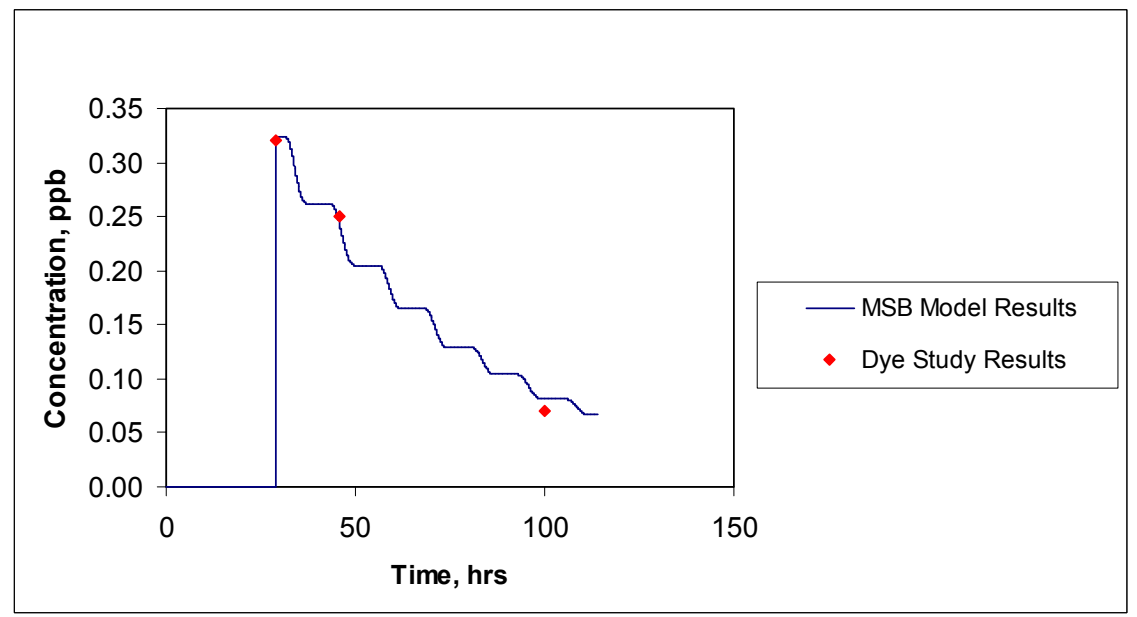

Figure 4: Comparison of the concentration predictions using the MSB model (for $b=0.25$ ) and the observed dye study results. 
The agreement between the model predictions and the field data appears to be very good for $b=0.25$. However, is this value of $b$ reasonable? To answer this question, we refer to an earlier study of the MSB model applied to cascading basins [2]. The authors investigated a system of three interconnecting basins. The inner embayment (basin 1) was subjected to pollution, basin 2 was used to adjust the ratio of basin volumes, $V_{2} / V_{1}$, and basin 3 was given a volume large enough to assume that there was no return flow from basin 3 to basin 2. Simulations for various values of $V_{2} / V_{1}$ were run and the results for the inner pollution-loaded basin were compared to those from an equivalent single basin system run using the pollution return-flow concept. The parameters, $b$ and $V_{2} / V_{1}$, were varied until the two simulations gave identical concentrations. This procedure was repeated for different values of $b$ (or $V_{2} / V_{1}$ ), allowing a mapping of $b$ onto the ratio of volumes, $V_{2} / V_{1}$. The results of this earlier study are shown in Figure 5.

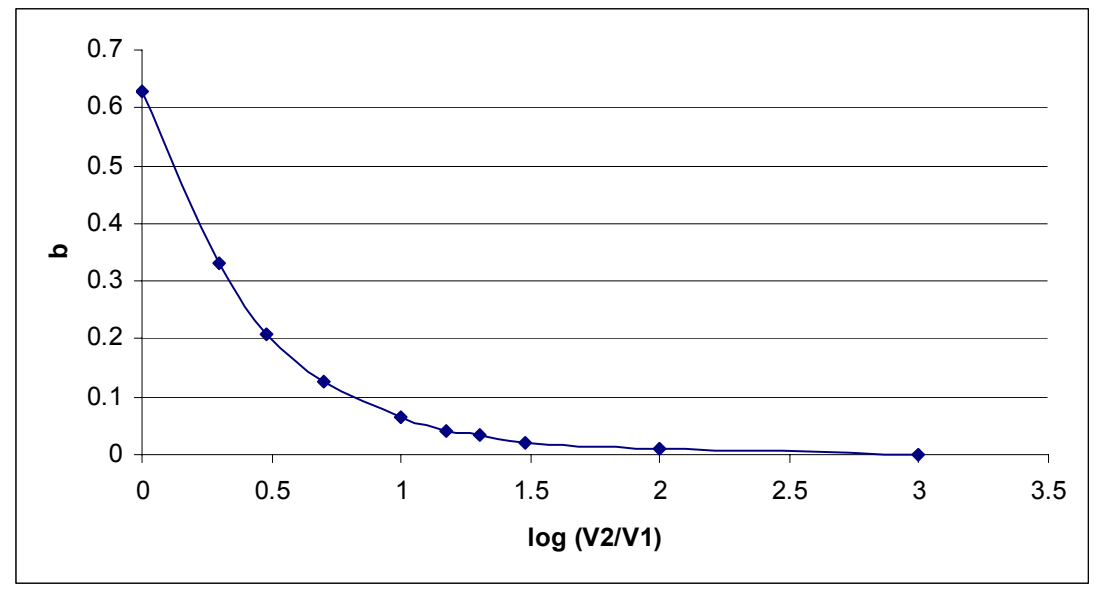

Figure 5: A mapping of $b$ onto the $\log$ of $V_{2} / V_{1}$ from Mecca et al. [2]. See text for details.

A value of $b=0.25$ is consistent with $\log \left(V_{2} / V_{1}\right) \approx 0.39$ or a value of $V_{2} / V_{1}$ of approximately 2.5 . In other words, the 'outer' basin equivalent volume is about 2.5 times the volume of the basin in question, in this case Great Salt Pond. The bathymetry of the region immediately outside the basin extending out to the likely reach of an ebb flow penetration is not inconsistent with such a volume. The reader can obtain some sense of this from the excerpt of the chart shown in Figure 6. An area similar to that of Great Salt Pond immediately outside the basin shows a bathymetry that is consistent with a volume two to three times larger than that of Great Salt Pond.

\section{Conclusions}

The MSB model for pollution flushing of tidal embayments has previously been validated against an analytical tidal prism model for well-mixed basins. 
However, until the present study, the MSB model has not been validated on a real embayment. An unpublished report on a Rhodamine dye study conducted in Great Salt Pond, Block Island in 1986 has provided an ideal opportunity to validate the present model. The results show that remarkably good agreement can be obtained between the model simulations and the dye study concentrations, for a suitably chosen value of the pollution return-flow parameter, $b$. It is interesting to note that the authors of the dye study concluded that "the flushing time of Great Salt Pond is very slow". The analysis from our study would suggest that this conclusion is really the result of a significant return flow of pollution as opposed to a slow discharge from the basin. It should be noted in closing that two of the authors (SJM and RWB) are undertaking a summative study of pollution return flow building on earlier work on this subject.

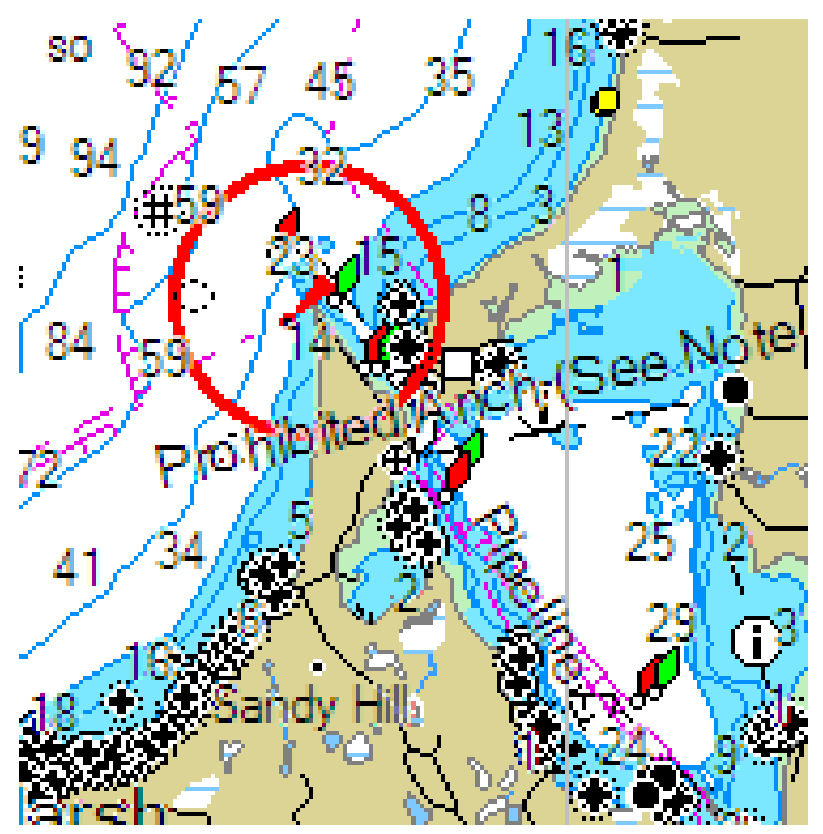

Figure 6: Great Salt Pond and the bathymetry immediately outside the basin.

\section{Acknowledgements}

John Tombarello and Christopher Wegemer are gratefully acknowledged for their efforts supporting this study while they were students in the Systems Dynamics Research Group in the Department of Engineering-Physics-Systems at Providence College. We would also like to thank the two individuals who were responsible for leading us to the dye study report, which was ultimately found in the files of one of the authors (GM): Chris Willy, Harbormaster on Block Island and Dr. Lorraine Joubert, Director of the Nonpoint Education for Municipal Officials at the University of Rhode Island, Cooperative Extension, Natural Resources Science, Coastal Institute in Kingston, Rhode Island. 


\section{References}

[1] Mecca, S.J., Severino, C. \& Barber, R.W., Pollution flushing models in Stella, Development and Application of Computer Techniques to Environmental Studies X, edited by G. Latini, G. Passerini and C.A. Brebbia, pp. 125-134, WIT Press: Southampton, UK, 2004.

[2] Mecca, S.J., Severino, C. \& Barber, R.W., Pollution flushing in cascading tidal basins, WIT Transactions on The Built Environment, 78, pp. 93-100, edited by M. da Conçeicao Cunha and C.A. Brebbia, WIT Press: Southampton, UK, 2005.

[3] Mecca, S.J., Barber, R.W. \& Tombarello, J., Alternative loading functions in the MSB pollution flushing model, WIT Transactions on Ecology and the Environment, 88, pp. 89-97, edited by C.A. Brebbia, WIT Press: Southampton, UK, 2006.

[4] Barber, R.W., Analytical modeling of pollution flushing in well-mixed tidal embayments, Chapter 17, Advances in Coastal Modeling, edited by V.C. Lakhan, Elsevier Science B.V., 2003.

[5] Hydrographic Study of Great Salt Pond, Block Island, Rhode Island, October 2-6, 1986. New England Technical Services Unit, Davisville, Rhode Island, September 1987, Department of Health and Human Services, Public Health Service, Food and Drug Administration, Shellfish Sanitation Branch, Unpublished.

[6] Sanford, L.P., Boicourt, W.C. \& Rives, S.R., Model for estimating tidal flushing of small embayments, Journal of Waterway, Port, Coastal and Ocean Engineering, 118 (6), pp. 635-654, 1992. 